\title{
SYNTHESIS
}

Synthesis

ISSN: 0328-1205

ISSN: 1851-779X

revistasynthesis@gmail.com

Universidad Nacional de La Plata

Argentina

\section{El eíron y otras reminiscencias griegas en la filosofía de John L. Austin}

\author{
Rodríguez Ponce, María Isabel \\ El eíron y otras reminiscencias griegas en la filosofía de John L. Austin \\ Synthesis, vol. 26, núm. 2, 2019 \\ Universidad Nacional de La Plata, Argentina \\ Disponible en: http://www.redalyc.org/articulo.oa?id=84662943008 \\ DOI: https://doi.org/10.24215/1851779Xe065
}

Esta obra está bajo una Licencia Creative Commons Atribución-NoComercial-Compartirlgual 4.0 Internacional. 
Artículos

\title{
El eiron y otras reminiscencias griegas en la filosofía de John L. Austin
}

The Eiron and Other Greek Reminiscences in the Philosophy of John L. Austin

Maria Isabel Rodriguez Ponce

Universidad de Extremadura, España

mirponce@unex.es

(iD http://orcid.org/0000-0003-3723-1892

\author{
DOI: https://doi.org/10.24215/1851779Xe065 \\ Redalyc: http://www.redalyc.org/articulo.oa?id=84662943008
}

Recepción: 01 Febrero 2019

Aprobación: 14 Mayo 2019

\section{Resumen:}

Este artículo analiza el poderoso influjo de la filosofía, la cultura y el teatro griegos en el trabajo y el discurso filosóficos de John L. Austin. El estudio se centra en dos vertientes estrechamente relacionadas: la peculiar recreación que el filósofo hace del eiron socrático y su inspiración directa en las estrategias retóricas y teatrales de los diálogos platónicos.

Palabras ClaVE: John L Austin, Eiron, Diálogos platónicos, Filosofía del lenguaje ordinario, Retórica, Teatro.

\section{Abstract:}

This paper analyses the powerful influence of Greek philosophy, theater and culture in the philosophical work and discourse of John L. Austin. The study focuses on two closely connected dimensions: the unique recreation that Austin makes of the socratic eiron and his direct inspiration from the rhetorical and theatrical strategies of Platonic dialogues.

KeYwORDS: John L Austin, Eiron, Platonic dialogues, Philosophy of Ordinary Language, Rhetoric, Theater.

\section{INTRODUCCIÓN}

Este trabajo se presenta como remate a una larga y detenida investigación sobre John L. Austin que se ha centrado en una profunda reflexión sobre la manera en que conectó el fondo de sus ideas filosóficas con sus modos retóricos de expresión, y que ha implicado colateralmente el análisis de la traducción al español de How to do things with words. En este proceso constantemente nos han salido al paso aspectos de la formación clásica de Austin que han influido poderosamente en la manera de enfocar su trabajo filosófico y en el legado intelectual que dejó tras de sí. Nuestro objetivo en este artículo es intentar desentrañar estas claves para observar las profundas y complejas raíces culturales de la propuesta filosófica de Austin.

Entran en este capítulo algunas cuestiones que hemos analizado con detenimiento en estudios previos, como la formación inicial de Austin en lenguas clásicas, sobre todo en griego, que le permitió por ejemplo traducir el Teeteto. En cuanto a la metodología, hemos destacado su fuerte influjo socrático y platónico, sobre todo por la forma de tratar los problemas, suspendiendo los argumentos para retomarlos más tarde. Autores como Miller (2001, pp. 19 y 59) y Leiber (1976, p. 65) no dudan en entroncar a Austin directamente con Sócrates en su estilo docente. Hay otros aspectos metodológicos de Austin en los que se detecta rápidamente un influjo de los filósofos griegos. Entre ellos están todos los que incumben a la utilización del trabajo colaborativo en cuanto a la investigación filosófica, y los que atañen a un determinado uso de los ejemplos, el humor y la ironía en la práctica docente de la filosofía.

En cuanto al uso metodológico del humor, no solo está muy presente en el título paródico de su obra fundamental, sino que se extiende a toda su práctica filosófica: clases, conferencias, seminarios... Austin siempre desafió conscientemente el riesgo de ser acusado de tomar la filosofía como un mero entretenimiento, y de hecho la mala comprensión de este aspecto por el entorno filosófico de la época fue asimismo una de las principales causas del rechazo de la filosofía lingüística. En esa línea, la opción de Austin también 
desafía la visión tradicionalmente aceptada de la filosofía como enemiga de lo cómico (Amir, 2013, p. 6), basada fundamentalmente en el agelastos, el filósofo que no ríe nunca porque está muy preocupado con ideas agobiantes (v. g. Pitágoras).

La investigación de Amir encuentra una serie de tradiciones que rompen con esta idea, entre las que se encuentran algunas directamente entroncadas con Austin. En primer lugar, la del filósofo ridículo, representado por Tales de Mileto, cuya anécdota de la caída al pozo es el origen de la esencial metáfora de la caída en la filosofía de Austin, como veremos más adelante. Amir (2013) señala que Platón, al hacer aparecer esta historia en el Teeteto, establece una línea directa entre la caída ridícula de Tales y la muerte de Sócrates (p. 7), que es la figura representativa de la siguiente tradición, la del filósofo cómico, que más claramente encarna Austin. Dice Amir (2013) que "Socrates uses a paradoxical duality as a tool for teaching philosophy. This method is expressed in an inextricable connection between the serious and the ridiculous or between the sublime and the low" (p. 7). Es el mismo programa filosófico-docente de Austin. Otra de las líneas que destaca Amir es la comparación de la filosofía con la comedia, muy presente en Platón y en los cínicos, y un aspecto central de la filosofía austiniana en el que vamos a detenernos demoradamente en estas páginas. Y la última tradición de las apuntadas por Amir que interesa para el análisis de Austin es la del ingenio (wit) como virtud, y no como herramienta retórica que debe ser denigrada.

Teniendo en cuenta todo este trasfondo en la relación entre filosofía y humor, resulta lógico que la filosofía lingüística, tal y como la entendía Austin, debía desvincularse del tratamiento pseudocientifico habitual que se daba a la filosofía en su época (Rorty, 1990 [1967], p. 93). La filosofía tenía que abrirse, desde la perspectiva de Austin, a un tratamiento más lúdico, más cercano a una nueva forma de arte, y en este sentido su visión retoma antiguas ideas platónicas que consideran que la filosofía se halla en un estado de tensión permanente entre la presión de las artes por un lado y de las ciencias por otro (Rorty, 1990 [1967], p. 127). Desde estas premisas, las actuaciones filosóficas de Austin pueden calificarse de performances totalmente conscientes permeadas por el humor y la ironía. El concepto de lo teatral, entendido al modo de la tragedia y la comedia griegas, domina el sistema filosófico de Austin desde sus principios fundacionales ${ }^{1}$ hasta su propia nomenclatura, por ejemplo, en cuanto al concepto central de performative utterances (Zwagerman, 2010, pp. 10-11).

En $H T W$ (sigla para How to do things with words a partir de ahora en este trabajo) aparecen ejemplos de usos metafóricos e imágenes que refuerzan esta interpretación: al hablar precisamente de los enunciados performativos, en la conferencia I los personifica a través de la aparición de un léxico con aroma teatral (masqueraders, to masquerade, disguise, to ape), incidiendo en cómo han conseguido engañar tanto a gramáticos como a filósofos; en la conferencia II reelabora la misma idea cuando dice que muestran el "gramatical make-up ofstatements", pero que no pueden ser verdaderos o falsos; cita a Shakespeare, concretamente en La Tempestad, cuando usa con ánimo metafórico el término sea-change (Miller, 2001, p. 35); y, además, uno de los puntos más espinosos de su teoría (la exclusión de los usos etiolados del lenguaje, usos "no en serio") está ilustrado con el soliloquio de un actor en escena, que es justamente el papel que él abordaba en sus clases y conferencias. ${ }^{2}$

Más concretamente, el tipo de actor que Austin prefería para desarrollar su labor filosófica, tanto investigadora como docente, era lo que Felman (1983) denominó "a jester": un bromista, un bufón (p. 95). En realidad, el personaje que Austin está modelando de una manera totalmente personal es la clásica figura del teatro griego antiguo, encarnada por Sócrates en los diálogos de Platón: se trata del eíron, el que se hace de menos, el que usa la ironía para sembrar la duda sobre la propia doctrina general que está tratando de demostrar en lugar de presentar verdades teóricas con un carácter definitivo y monolítico.

\section{El EÍron}

Acabamos de mencionar que en $H T W$ Austin se atribuye el papel del eiron. Este es uno de los aspectos en los que este filósofo muestra de forma más clara su vinculación con la manera de hacer filosofía de los clásicos 
griegos, más específicamente de Sócrates, que en los diálogos de Platón podía representar tanto el papel de eíron ${ }^{3}$ como el de alazón (Lang, 1990, p. 107), algo que también sucede en cierta manera con Austin.

Eíron y alazón son las dos caras de una misma moneda, dos figuras arquetípicas que van íntimamente ligadas en la comedia griega antigua, y que son muy visibles en Aristófanes, por ejemplo. En su Ética a Nicómaco Aristóteles certifica la adscripción de estas figuras teatrales y comenta sus características enfocándose más en un ámbito moral general, cuando habla de la sinceridad: "el jactancioso es el que pretende reputación en cosas que no le pertenecen, o en mayor medida de lo que le pertenece, mientras que el irónico niega lo que le pertenece o le quita importancia" (Pallí, 1985, p. 230). Aristóteles menciona expresamente como ejemplo de irónico a Sócrates, y entre ambas categorías considera más agradable y mejor al irónico, siempre que no se exceda en la minimización de sus méritos, ya que los extremos se tocan y la ironía puede convertirse en jactancia (Pallí, 1985, p. 231). En la comedia antigua griega el alazón alardea de lo que realmente no sabe o no tiene, y el eíron se desprecia a sí mismo, se hace de menos, pero suele acabar triunfando sobre su oponente y, en cierto modo, burlándose de él. Como señala Ballart (1994), no transcurriría mucho tiempo sin que este binomio teatral encontrase un correlato mucho más profundo en la filosofía (p. 40). De hecho, este último arquetipo del eíron, mutatis mutandis, es el que Platón toma para el personaje de Sócrates en sus diálogos. ${ }^{4}$

\subsection{Eíron, eironeía, ironia}

Es muy revelador observar la trayectoria de estos conceptos desde el establecimiento del personaje de Sócrates en el arquetipo del eíron. Por ejemplo, por lo que respecta a Aristóteles, Gooch (1987) valora como desconcertante el análisis que el filósofo hace de estas figuras (p. 98). Aunque ambos están lejos de la verdad, el eíron y la eironeía que se deriva de él resultan más aceptables que el alazón porque comparten una importante cualidad con el verdadero amante de la verdad: se inclinan más a subestimarla que a sobreestimarla, a pesar de que la eironeía se había asociado inicialmente con bribones y burlones por el propio Aristóteles. A este respecto, ha habido un notable debate en torno tanto al concepto como a la evolución de la palabra desde su uso en Platón y su posterior latinización. Según Vlastos (1991), eíron en ático tenía connotaciones desfavorables, incluso insultantes, como se ha visto. Con el paso del tiempo perdió esos matices y en latín ironia no es negativo, sino que tiene tonos de urbanidad, elegancia y buen gusto. En opinión de Vlastos, fue la imagen de Sócrates como eiron paradigmático la que produjo un cambio en la connotación previa de la palabra.

La traducción que Cicerón hizo al latín de la eironeía aristotélica también reforzó la visión de la ironía socrática como subestimación y modestia (Lane, 2010, p. 240). La polémica se generó al contrastar esta interpretación aristotélica de eironeía ('autodeprecación, modestia') con el sentido de la misma palabra en los textos aristofánicos ('engañar, disimular, ocultar mediante fingimiento') (Lane, 2010, p. 248). Vlastos opina que Platón utiliza ambiguamente la palabra según el diálogo que tomemos en perspectiva, y que, por ejemplo, en el Gorgias o en el Banquete estamos más cerca de un sentido aristotélico de eironeía (Lane, 2010, p. 249). Para otros autores, como la propia Lane, esto no está tan claro.

En cualquier caso, como indica Louw (2012), la relación entre eironeía e ironia no interfiere en la interpretación de la ironía socrática (p. 30), cuyas funciones no siempre son fáciles de dilucidar (p. 60). Nehamas (en Lane, 2010, p. 245) sugiere que su objetivo es simplemente generar misterio, o servir del filtro, para que solo puedan acceder a la filosofía los que sean capaces de descifrar esta carga irónica (Lane, 2010, p. 243). Además de acercarse más a la verdad desde una postura de autodeprecación y de llevar al interlocutor a una nueva realización del conocimiento (Louw, 2012, p. 59), hay una vertiente de la ironía socrática quizás menos evidente y que puede tener también otras funciones. 
Según Louw (2012), en Sócrates no solo hay una ironía verbal, sino también una ironía física, más difícil de identificar (p. 37). En el Banquete se pone en boca de Alcibíades una cita de las Nubes de Aristófanes en la que se comenta la manera de caminar de Sócrates, orgulloso como una oca y mirando a ambos lados, con aire de superioridad. Asimismo, hay varias referencias a que Sócrates iba sin zapatos en cualquier época del año. Alcibíades menciona que los soldados lo miraban de reojo por este motivo, pensando que Sócrates les humillaba (Louw, 2012, p. 37), ya que ellos iban calzados. Estas actitudes vitales más espartanas que atenienses, que seguramente Sócrates no llevaba a cabo por necesidad, eran irónicas, una reacción deliberada y crítica a la situación política de su época (Louw, 2012, pp. 73-75). En cualquier caso, algunos de estos aspectos descritos bajo el rótulo de ironía física tienen un valor dramático: por ejemplo, los rasgos físicos de cotidianidad adscriben el personaje de Sócrates fundamentalmente al género cómico.

Por lo que se refiere a Austin, parece que al revivir el arquetipo del eíron socrático elige su versión más primigenia y genuina, como en tantas otras de sus opciones (por ejemplo, en la creación de su terminología filosófica). Es decir, se trata del eíron burlón, el más cercano al teatro griego, que con su actitud pretende hacernos dudar y pensar. Por otra parte, la descripción de una ironía física en el Sócrates platónico es asimismo un detalle digno de consideración, pues mucha de la ironía que Austin despliega en $H T W$ tiene también un carácter físico, de trabajo con el cuerpo (caídas, hundimientos, resbalones, desplazamientos...). Estos elementos introducen en la filosofía austiniana un valor de acción dramática de impacto equiparable al de la ironía verbal estándar, y no hay que desdeñar que parte de su inspiración esté tomada de la caracterización de Sócrates en los diálogos platónicos, además del referente de Tales de Mileto y de otros antecedentes más cercanos de la cultura popular coetánea de Austin (algunos comediantes de slapstick), sobre lo que profundizaremos más adelante.

\subsection{Eíron/alazón y la genealogía del philosophus gloriosus}

Si se retoma la dualidad eiron/alazón para profundizar un poco más en su segundo componente, Frye (1957, p. 39) señala que entre los tipos más populares de alazón, están, además del miles gloriosus, el "obssesed philosopher", el philosophus gloriosus del que Luciano ofrece el máximo exponente en su Subasta de vidas (Calero, 1988) y en los Diálogos de los muertos (Navarro, 1992, pp. 153-225). Este tipo llega a encarnarse incluso en personajes como Fausto, el hombre sabio que insatisfecho por la limitación de su conocimiento vende su alma al diablo. En HTW Austin juega principalmente el papel de eíron pero, como Sócrates, lo mezcla con el de alazón y presenta una marcada reminiscencia de la figura clásica del filósofo ridiculizado (Tales de Mileto), e incluso de Fausto, a través de la presencia de un fraseologismo como to play Old Harry with.

La tradición de la ridiculización del philosophus gloriosus hunde sus raíces en la sátira menipea, que es de donde la toma Luciano, a través de Menandro. Es muy curioso observar cómo la peculiar caracterización del eíron-alazón austiniano sigue todo un complejo recorrido que tiene su punto de partida en el Sócrates de los diálogos platónicos, pero que también sigue a los philosophus gloriosus que van pespunteando la historia de la sátira. ${ }^{5}$ Frye (1957) describe esta última como el reverso de la normalidad, como una vía de escape (p. 233). Toma como ejemplo a Tristram Shandy y a Don Juan (recordemos que Felman identifica a Austin con Don Juan en su estudio de 1983) para ilustrar "the constant tendency to self-parody in satiric rhetoric which prevents even the process of writing itself from becoming an oversimplified convention or ideal" (Frye 1957, p. 234). Al mismo tiempo, Frye nos muestra que en su tercera fase la sátira es esencialmente una técnica de desintegración, de fragmentación. Todas estas características las incorpora Austin al elegir eironizar su discurso, incluso en el aspecto de la fragmentación, que es la piedra de toque de su método de análisis lingüístico. 
La voracidad con la que Menipo y Luciano cargan contra la pedantería filosófica tiene un reflejo en el ámbito anglosajón. John Lyly, ilustre antecesor de Austin en el Magdalen College de Oxford en la época isabelina, escribe una obra, Campaspe, en la que se vuelve a ridiculizar a los filósofos: se presenta a Platón y a Aristóteles como dos aburridos, mientras que Diógenes, ${ }^{6}$ en su papel de bufón real, "les roba el show" (Frye, 1957, p. 230). John Lyly escribe también Euphues o la anatomia del ingenio (wit), concepto esencial en Austin. Pero el gran exponente de la sátira menipea en inglés es Anatomy of Melancholy, de Burton. Tanto en este caso como en el de Lyly, al hablar de Anatomy en el sentido de 'disección', 'análisis', estamos tratando con un género en sí mismo: "The digression of the miseries of scholars, of the satire on the philosophus gloriosus" (Frye, 1957, p. 311). Esta corriente alcanza su punto culminante con la ya mencionada Tristram Shandy de Sterne, en la que, aun siendo una novela:

the digressing narrative, the catalogues, the stylizing of character along 'humor' lines, the marvellous journey of the great nose, the symposium discussions, and the constant ridicule of philosophers and pedantic critics are all features that belong to the anatomy (Frye, 1957, p. 312).

Podría decirse que $H T W$ se ubica conscientemente, a su manera, en este género de la Anatomy, con el que muestra unas características recurrentes: ironía, forma dialogada, sátira, digresión, fragmentación, humor, ridiculización de la erudición y la pedantería (sobre todo en los filósofos), siguiendo la tradición crítica hacia el philosophus gloriosus. Es una línea que se inicia en los griegos y latinos (Menipo, Menandro, Luciano, Boecio) y que tiene continuidad a lo largo de toda la historia (al igual que la comedia, a la que se vincula) particularmente en el contexto anglosajón, como hemos visto.

\section{Los diÁlogos Platónicos y EL TEATRo griego CON RESPECTO A AuSTIN}

La presencia de un eiron de inspiración socrática en Austin acaba conduciendo indefectiblemente a una reflexión sobre la relación entre los diálogos platónicos y el teatro griego. Como explica Lledó (2015 [1984], pp. 50-51), Platón es el primer filósofo en escribir su pensamiento, ya que en su tradición filosófica la escritura era secundaria. Lledó (2015 [1984], p. 66) señala cómo el "adanismo" de la filosofía platónica, especialmente en lo que se refiere a la forma dialogada en la que se materializa, plantea algunas dificultades: principalmente que, al no tener una tradición escrita inmediata, puesto que no había un antecedente de prosa filosófica (Nussbaum, 2015 [1995], p. 180), la adscripción del nuevo género resulta difícil de determinar. Realmente, su género de referencia es el teatro, ${ }^{7}$ y en opinión de algunos estudiosos la pretensión de Platón era incluso reemplazar culturalmente a Aquiles, Edipo y Pericles con su propio héroe, Sócrates. (Kahn, 1996, p. 15)

\subsection{El influjo de la tragedia}

Para empezar, Platón concibe sus diálogos en tetralogías, como las obras trágicas (Puchner, 2010, p. 4), y no faltan los teóricos que observan una línea de desarrollo desde Esquilo, Píndaro y Sófocles hasta Platón y que señalan la tragedia entre los antecedentes lógicos de la filosofía platónica. Kuhn (1941) explica que hay una evolución entre la tragedia y la filosofía como caminos alternativos para lidiar con el problema del sufrimiento: la primera a través de la catarsis; y la segunda, por la contemplación (p. 1). Este estudioso (Kuhn, 1941, pp. 13, 16-17) advierte claramente de que hay un abismo entre el drama griego y los diálogos platónicos, que son dramáticos solo de una manera limitada, pero aun así reconoce que Platón desarrolla un esquema de pensamiento basado en la tragedia, y determina de forma concreta posibles antecedentes de este tipo en Platón.

Por ejemplo, afirma que las palabras de Sócrates en el comienzo de la Apología pueden conectarse con algunas intervenciones de Odiseo sobre la verdad en el Filoctetes de Sófocles (Kuhn, 1941, p. 7); compara 
una escena de Prometeo encadenado (Esquilo), en la que tres personajes se acercan al sufridor Prometeo y reflexionan sobre el poder de Zeus, con la estructura del Gorgias, un diálogo sobre el poder y la justicia (Kuhn, 1941, p. 8); o una referencia que Platón hace a Zethus y Amphion, dos hermanos que aparecen en Antiope (Eurípides), muy distintos entre ellos (uno activo, centrado en el cuerpo; y otro contemplativo, inclinado a la mente), se relaciona con el personaje de Sócrates en el Gorgias, que parece integrar en una sola persona a Zethus y a Amphion (Kuhn, 1941, p. 10). De hecho, las citas del Gorgias tienen una importancia capital en la reconstrucción de algunos fragmentos de la Antiope. (Martínez Bermejo, 2013, p. 29)

En la filiación de este parentesco, Kuhn (1941, pp. 37-38) parece inclinarse más hacia Esquilo, ${ }^{8}$ y afirma que puede detectarse un influjo de la trilogía de este último (la Orestiada: Agamenón, Las Coéforas y Las Euménides) en la trilogía de Platón (Timeo, Critias y Hermócrates). Por lo que se refiere en concreto al personaje de Sócrates en los diálogos de Platón, a Kuhn le parece que está retratado como un pariente de los héroes de Esquilo y Sófocles, a la manera de Aquiles o Tiresias: sincero, firme ante los peligros de la batalla, invariable ante una muerte inminente, $\mathrm{e}$ "ironically disguising the adamantine quality of his mind behind a show of doubt and wavering". (Kuhn, 1941, p. 10)

En su revisión de la relación de los diálogos platónicos con la tragedia griega, Puchner (2010) toma como referencia fundamental el Fedón, en el que se relata la muerte de Sócrates en prisión poco a poco, de forma muy trágica, después de tomar el veneno, mientras se discute sobre la inmortalidad del alma. Puchner compara la idea del alma encerrada en el cuerpo (y liberada con la muerte) con el hecho de que Platón decide encapsular la teoría de las ideas en una forma dramática, que es quizás la que menos le conviene desde el punto de vista lógico, pues llena la exposición filosófica de distracciones e impurezas. La razón para ello es que "los argumentos abstractos y filosóficos sobre la muerte necesitan conectarse y cargarse a través de los deseos y miedos de personajes tridimensionales" (p. 14). Esto es exactamente lo mismo que hace Austin cuando para explicar los enunciados performativos los encarna a través de la personificación, como hemos visto más arriba: consigue que algo abstracto y complejo se vuelva concreto y accesible.

\subsection{El influjo de la comedia}

Las raíces teatrales del diálogo platónico no se detectan solo en el género trágico, sino también en la comedia griega antigua. Puchner (2010) expone cuáles son las características de los diálogos que los acercan a la comedia (pp. 63-64): el relativo estatus social bajo de Sócrates, la importancia de la vida cotidiana (aspecto, ropa, calzado, hábitos alimenticios, bebida, hábitos de sueño); la atención que se presta a la higiene, la mayor relevancia de los hechos materiales de la vida, el constante interés en asuntos amorosos. En su estudio este autor analiza las obras teatrales que a lo largo de la historia han tenido como tema a Sócrates, y llega a la conclusión de que es un personaje más fácil de llevar a la comedia que a la tragedia (Puchner, 2010, p. 71).

Uno de los motivos de esta tendencia es que Sócrates, desde su aparición como personaje en el teatro griego, es presentado como lo que Puchner (2010) denomina "a comic stage philosopher" (p. 64), caracterización que se mantiene en los diálogos platónicos. Cuando la descripción de filósofos y de ideas adopta un molde dramático, la tendencia a la comedia es casi inevitable, porque habitualmente estamos refiriéndonos a individuos dominados por una idea fija que marca sus acciones y que les hace incapaces de reaccionar a lo que tienen alrededor, o al menos así lo explica Bergson refiriéndose a Tales de Mileto (Puchner, 2010, p. 16). Austin cumple con esta inclinación a lo cómico determinada por el estilo teatral de su filosofía y se ríe incluso de sí mismo como categoría: se burla irónicamente de la figura de los filósofos obsesionados con fetiches como la oposición verdad/falsedad, por ejemplo.

Más arriba mencionábamos la ironía física como un aspecto de corte dramático que adscribía al personaje de Sócrates a la comedia. Efectivamente, la fisicidad, la corporalidad, es un rasgo asociado a la acción cómica. Por ejemplo, en el Banquete, que es uno de los diálogos con más carga cómica, Platón presta una atención 
constante a la interacción física entre los personajes (Puchner, 2010, p. 17), y se contraponen las teorías abstractas con las realidades corporales; mejor dicho, estas últimas se emplean para que las primeras tomen forma. Se trata siempre de procesos de concreción de lo abstracto. Puchner (2010) lo explica con claridad: en el Banquete Diotima presenta una teoría del amor que rechaza el cuerpo y se muestra partidaria de las ideas (pp. 18-19). Pero esto se hace a través de una declaración de amor de Alcibíades a Sócrates, con quien revela haber dormido sin ser amantes. Se trata de una acción que confronta las dos ideas: el amor de los cuerpos (erótico) y el amor de las voluntades (philía). Austin interiorizó de una manera muy potente y profunda todos estos mecanismos platónicos. Lo físico está muy presente en sus ejemplos e imágenes (por ejemplo, lo resbaladizo, las caídas, los hundimientos, como ya se ha mencionado), siempre con una intención y un efecto cómico, pero al mismo tiempo unido a una reflexión filosófica subyacente, a un contenido abstracto que se quiere transmitir mejor. Por eso prácticamente todos los momentos de $H T W$ en los que hay caídas están vinculados a un cuestionamiento del conocimiento, de las ideas ya establecidas.

\subsection{Un nuevo género mixto}

Ya en otro plano, la vinculación de los diálogos platónicos a la comedia viene por un deseo de antítesis por parte de Platón. Aunque la colaboración de todo tipo entre filósofos y autores teatrales en la Grecia antigua era constante (se dice que incluso Sócrates compuso tragedias en colaboración con Eurípides, Puchner, 2010, p. 4), la comedia y lo cómico habían sido totalmente defenestrados en la opinión de Platón como expresión máxima de cierto tipo de poesía vulgar, y así lo refleja en distintas partes de su obra (Puchner, 2010, p. 5). A pesar de ello, Platón era muy consciente del poderoso influjo que el teatro ejercía en los griegos, por su coetaneidad, por sus mensajes directos y sugestivos, y no dudó en pasar por alto las contradicciones que esto suponía con su propia teoría y en emplear todos los recursos constructivos que esta realidad social le ofrecía. Lo hizo también con un afán de superación del propio género, ya que la aspiración de Platón era que la filosofía sustituyera a la comedia en el gusto y en la educación de los griegos. Así que escribir diálogos filosóficos era una manera de crear una nueva forma superior de poesía que lograba sintetizar tragedia y comedia (Salas Abad, 2015, p. 30), siguiendo la famosa recomendación de Sócrates al final del Banquete (Racket, 2013, p. 45). Puchner (2010, p. 20) sostiene que esa mezcla es más importante de lo que se ha querido ver, pues no se trataba solo de mezclar risa y llanto, sino abstracción y corporeidad en el sentido antes apuntado, en el de un mayor impacto y una mejor comprensión de las ideas filosóficas.

Asimismo, la transformación del diálogo cómico en diálogo filosófico implicaba una fuerte reacción a Aristófanes que cristaliza en diferentes direcciones. Por una parte, los diálogos de Platón contrarrestan la imagen ridícula de Sócrates que Aristófanes había presentado en sus comedias, fundamentalmente en las Nubes, donde se le caracteriza con todos los atributos de un sofista corruptor de la juventud (Salas Abad, 2015, pp. 26-27). Precisamente este cargo, sumado a la ofensa a los dioses, fue el que fundamentó la condena y posterior ejecución de Sócrates, así que su reivindicación platónica en los diálogos cobra una especial fuerza y es un alegato contra el uso de la comedia planteado por Aristófanes, que desde el enfoque de Platón podría calificarse de amoral.

La mixtura de los géneros también repercute en la propia creación del personaje de Sócrates por parte de Platón. Como explica Puchner (2010), el Sócrates platónico toma de la comedia la ruptura de las normas sociales; y de la tragedia, la ejemplaridad mítica y su carácter único (p. 22). Sigue diciendo este autor que, al igual que le sucede al propio diálogo, este nuevo y extraño héroe filosófico supera los dos géneros, es a la vez risible y admirable, ejemplar y común. Aquí late la idea platónica de que la filosofía es una cuestión de carácter, algo que se manifiesta en la personalidad. La filosofía se encarna, está viva, y se manifiesta más en la conducta vital de alguien que en sus obras filosóficas. Puchner (2010) menciona a Wittgenstein y Foucault como continuadores de ese pensamiento (p. 22). Efectivamente, Wittgenstein se manifestó muy claramente a este respecto sobre todo en el aspecto formal, incluso renunciando a la propiedad de sus ideas si no llevaban 
un sello que las marcara como suyas (Leiber, 1976, p. 58), dada la extraordinaria similitud de contenidos entre su trabajo y el de otros filósofos, como el propio Austin, sin ir más lejos. Austin continúa esta idea platónica, hasta el punto de que este alto nivel de exigencia en la personalización de su discurso le pasó una cara factura en la recepción de su filosofía y lo sumió, en cierta manera, en el olvido académico.

\subsection{La herencia estructural del teatro en los diálogos}

La herencia teatral en los diálogos de Platón no solo se puede documentar desde el punto de vista de las ideas y los contenidos, sino que ha sido estudiada también desde una perspectiva puramente formal y estructural que no hace más que confirmar las conclusiones que acabamos de exponer. Por ejemplo, Ortega Máñez (2012) piensa que no se ha insistido bastante en la conexión entre la creación del diálogo filosófico y la creación del propio diálogo teatral, con la invención del segundo actor por parte de Esquilo (pp. 291-292). Los acentos teatrales resuenan en los diálogos platónicos en primer lugar escénicamente, pues los personajes siempre están situados en un contexto preciso; y, en segundo lugar, dramáticamente, ya que los personajes están en acción, aunque parezca que solo hablan: "aunque en teatro cada palabra es activa, en este caso más aún, porque aquí las palabras constituyen la acción por excelencia, ya que la actividad filosófica se realiza a través de palabras" (Ortega Máñez, 2012, p. 293). Como matiza Nussbaum (2015 [1995]), la acción se sustituye por la argumentación (pp. 187-188). Estrictamente, los personajes de Platón hacen filosofía hablando, en el sentido del principio rector de la filosofía austiniana, "hablar es hacer, actuar".

En perfecta sintonía con lo anterior, otro elemento estructural de la acción dramática que comparten los diálogos platónicos y el teatro griego antiguo es el élenchos, que a veces parece asociarse exclusivamente a la metodología socrática. Sin embargo, también es una característica de la tragedia; por ejemplo, está presente en Antígona, como indica Nussbaum (2015 [1995], pp. 185-186). Hay una diferencia sustancial, y es que el élenchos trágico opera sobre sentimientos, mientras que el élenchos platónico lo hace únicamente en el plano intelectual (Nussbaum, 2015 [1995], pp. 190-191).

Ya por último, en la estela de una abundante tradición bibliográfica previa, Bádenas (1984) analiza los diálogos platónicos como piezas teatrales, aplicándoles la estructura y conceptos de estas últimas (prólogo, actos, conclusión, epílogo; agón, narrador, personaje principal, personaje central, oponente, resis...). Bádenas (1984, p. 10) expone que los diálogos de Platón siguen un esquema puramente agonal que articula la acción a la manera del teatro (de una forma más compleja) y en el que, efectivamente, Protágoras, Gorgias o el propio Sócrates se muestran como estereotipos análogos a los héroes teatrales (Creonte, Edipo, Cleón). Por ejemplo, en el Protágoras, Sócrates va desvelando poco a poco sus verdaderas intenciones, acaba suplantando al protagonista y se convierte de oponente de unas tesis en defensor de las mismas, aunque variando los criterios, como harían tantos héroes de comedia (Bádenas, 1984, p. 62).

La naturaleza eminentemente teatral de los diálogos platónicos se pone de manifiesto en su propia configuración. Por ejemplo, en ellos hay un predominio claro de los elementos dialogados sobre el monólogo o intervención larga (Bádenas, 1984, p. 241), con el fin de favorecer la idea dramática de acción. No obstante, el diálogo más frecuente entre los platónicos es el de tipo asimétrico, ${ }^{9}$ ya que le otorga preponderancia al personaje fijo, que es Sócrates, quien además utiliza esta herramienta como su propio medio de investigación filosófica (p. 244). Las intenciones metodológicas de Austin al inspirarse en estas técnicas son idénticas. Por último, Platón escoge el diálogo como forma de escritura filosófica para homenajear a su maestro Sócrates y a su metodología. Lo que realmente hizo Platón fue resucitar a Sócrates, darle la vida eterna a través de la fórmula del diálogo teatralizado, de la magia del teatro (Puchner, 2010, p. 10), para compensar de algún modo la inmensa injusticia que se había cometido contra su figura histórica. Al situarse en una línea de continuidad metodológica con ellos, Austin sigue homenajeando y reavivando a su manera una idea prístina del trabajo filosófico y de cómo debe ejecutarse. 
La estructura agonal no es el único aspecto que aporta a los diálogos platónicos su tinte teatral. Siempre es necesario poner el agón en relación con otras unidades estructurales del teatro griego antiguo, como, por ejemplo, el prólogo, que tiene un papel especial en este conjunto de relaciones. Bádenas (1984, p. 262) habla de una presentación sinuosa de Sócrates en los diálogos, y Puchner (2010, pp. 23-26) analiza este aspecto utilizando conceptos dramatúrgicos propios de la tragedia griega. Como en esta última, Platón se plantea una acción única, pero la forma en la que la acción y los argumentos se retroalimentan en los diálogos resulta muy compleja. Platón maneja las categorías de peripecia y anagnórisis descritas por Aristóteles de una manera muy peculiar. No hay una sola peripecia ni un solo momento de reconocimiento que luego llevan a una conclusión única. Estos elementos se multiplican en diferentes direcciones, se mueven en círculo, recomienzan una y otra vez... Platón crea un molde dramático laberíntico: muchas veces no se llega a una conclusión y los diálogos acaban abruptamente. Se trata de una manera formal, retórica, de representar la dificultad en llegar a la verdad. Esta es la misma estrategia que, como hemos comentado en diferentes apartados de este trabajo, adopta Austin premeditadamente, con su sistema de caidas, de constantes reinicios, de no querer llegar rápidamente al núcleo de la cuestión tratada. Este huir del centro se refleja muy bien en el uso constante y premeditado de la aporía y de los finales inacabados, inspirados en las conclusiones de los diálogos platónicos.

\section{Austin y el Teeteto}

Además de su conocimiento exhaustivo de la filosofía, el teatro y la cultura de la Grecia antigua, la traducción que Austin hizo del Teeteto de Platón influye decisivamente en muchos aspectos de $H T W$, empezando por su propia estructura. En el Teeteto nos hallamos frente a una primera definición en la que se habla del saber como percepción y se explican las diferencias entre el filósofo y el orador. A continuación, la segunda definición entiende el saber como opinión verdadera, y se ofrece una digresión fallida sobre la opinión falsa. En la tercera definición se propone que el saber equivale a opinión verdadera acompañada de una explicación. Y se concluye con la imposibilidad de definir el saber. Del mismo modo, en $H T W$ hay muchos cambios de definición, respuestas fallidas, muchos recomienzos, y también se termina sin llegar a ningún resultado concluyente. Es decir, que el destacado peso de la aporía en el trabajo filosófico de Austin tiene un punto de referencia esencial en la importancia que en el Teeteto se concede a este aspecto, más aún si se considera que en esta obra Platón vuelve a la representación de Sócrates que había hecho en los primeros diálogos, más fiel al Sócrates histórico, a sus planteamientos sobre el conocimiento y a sus metodologías (Kahn, 1996, p. 160).

En cuanto a los propios contenidos y la metodología, la reflexión sobre el saber que representa el Teeteto está centrada en el fetiche filosófico verdad/falsedad, pero introduce muchos intereses que coinciden con los del propio Austin, como cuando Sócrates, para defender a Protágoras, asegura que lo fundamental de la argumentación consiste en sustituir la oposición verdad y falsedad por la de utilidad y perjuicio (Kahn, 1996, p. 150), que son las parejas de términos en las que pueden evaluarse, respectivamente, los enunciados constatativos y performativos de Austin. En este diálogo Sócrates va introduciendo una serie de argumentos que van minando la autoridad del tótem filosófico verdad/falsedad; se trata de una estrategia recreada por extenso posteriormente en filosofía austiniana. Por si fuera poco, aparece en el Teeteto la figura de Pródico de Ceos, el sofista que se centraba en el uso correcto de las palabras y en el estudio de los sinónimos. En el afán de Pródico por las distinciones lingüísticas se ha querido a veces ver un antecedente del método socrático de las definiciones. Lo que sí está claro es que la metodología del análisis lingüístico desarrollada por la filosofía de Austin tiene aquí un claro anclaje, una vez más relacionado con la ironía. ${ }^{10}$

Y quizás el influjo más interesante del Teeteto en Austin provenga de la larga digresión sobre la naturaleza desinteresada y libre del filósofo en contraposición al orador, movido por el interés y esclavo de su señor y de cierto tipo de discurso. Y en esta comparación Sócrates pone como ejemplo a Tales de Mileto y la ya mencionada anécdota de su caída en un pozo cuando estudiaba las estrellas, lo que provoca la burla de una 
sirvienta tracia ${ }^{11}$ "porque quería saber las cosas del cielo, pero se olvidaba de las que tenía delante y a sus pies" (Santa Cruz, Vallejo, Cordero, 1988, 241, 174a, 174b, 174c, 174d).

Por supuesto, esta caracterización presenta sus concomitancias, en cierto modo, con la del eíron y la del philosophus gloriosus, que hemos analizado anteriormente en estas páginas. Pero lo que más nos interesa aquí es la idea de la caída, que es una imagen fundamental en muchas metáforas y ejemplos de Austin, siempre en un contexto humorístico e irónico. ${ }^{12}$ Ya hemos mencionado más arriba que casi todos los pasajes de $H T W$ donde están presentes los hundimientos y caídas, incluso potencialmente, son momentos esenciales en los que se plantean dudas, en los que se cuestiona el conocimiento (Felman, 1983, p. 119; Zwagerman, 2010, p. 142). El hecho de que el personaje que Austin crea para sí mismo en su obra, a la manera de un Charlie Chaplin, un Harold Lloyd, un Buster Keaton, o de cualquier otro comediante de slapstick, esté constantemente cayéndose humorísticamente y volviéndose a levantar a través de medios retóricos como la metáfora, en un recorrido constante de la dimensión vertical, tiene múltiples raíces clásicas.

En primer lugar, está relacionado con la paralela importancia de otro mecanismo retórico en este filósofo: "Like Don Juan's life, austinian research is thus modeled on anaphora, on repetition of beginnings" (Felman, 1983, p. 63), que supone otro recorrido constante de la dimensión horizontal, de la línea del tiempo. Y todo ello tiene un sólido anclaje en la cultura clásica griega. La esencia de la tragedia griega es la caída de los héroes. En los grandes libros clásicos (Iliada, Odisea) se siguen unos ciclos épicos de ascenso y caída tanto de los líderes como de los enemigos (Frye, 1957, pp. 348-349). Estas caídas tienen un sentido trágico que es parodiado por Austin en su obra. También estos libros, en su sentido cíclico, están basados en un retorno: Grecia-TroyaGrecia en la Ilíada; de Ítaca a Ítaca en la Odisea; de Troya a una nueva Troya en la Eneida (Frye, 1957, p. 318). Es una idea cuyo influjo habría que tener en cuenta en la propia estructura de $H T W$, sobre todo en cuanto al concepto de fresh start, de reinicios constantes (anáfora). Austin no hacía esto casualmente, sino con deliberación y propósito. ${ }^{13}$

Por otra parte, Tales de Mileto es considerado el primer filósofo y Austin busca conscientemente una identificación con este enfoque primitivo, puro y naif de la filosofía, también a través de este recurso irónico de la caída, del mismo modo en que lo hace en el resto de planos de su obra, desde su propia terminología, por ejemplo. Por lo que respecta a la imagen cercana del hundimiento, crucial en Austin, sus raíces platónicas son asimismo innegables. En La República (533d) encontramos el siguiente fragmento, que reivindica la superioridad del método dialéctico sobre otras técnicas de conocimiento y enseñanza:

El método dialectico es el único que, echando abajo las hipótesis, se encamina hacia el principio mismo para pisar allí terreno firme; y al ojo del alma, que está verdaderamente sumido en un bárbaro lodazal, lo atrae con suavidad y lo eleva a las alturas, utilizando como auxiliares en esta labor de atracción a las artes hace poco enumeradas. (Pabón y Fernández, 1969, pp. 35-36)

Encontramos aquí varias imágenes metafóricas relacionadas entre sí y vinculadas a la idea de desplazamiento en la dimensión vertical a partir de la horizontalidad de un supuesto terreno. ${ }^{14}$ Esto remite claramente a este otro fragmento de $H T W$ :

So far then we have merely felt the firm ground of prejudice slide away beneath our feet. But now how, as philosophers, are we to proceed? One thing we might go on to do, of course, is to take it all back; another would be to bog, by logical stages, down. (Austin, 1975, p. 13)

Se muestran aquí solo algunas de las metáforas convencionales de $H T W$ que representan un contraste entre horizontalidad y verticalidad en la que los pensadores o los propios conceptos, a medida que se desplazan, sufren un proceso de hundimiento que no se valora como negativo, al contrario de lo que predica la teoría de la metáfora conceptual. La metáfora de hundimiento representada por to bog down, con su fuerte antecedente platónico, sobrevuela toda la obra y algunos estudiosos (Miller, 2001, p. 170) la interpretan como la tenaz resistencia de Austin a rematar sus trabajos de una manera conclusiva, en una línea de pensamiento plenamente socrática. 
Esta reflexión se adentra en un plano todavía más profundo mediante el análisis de un aspecto que funde la presencia estructural de la retórica en Austin con el influjo que recibe de Platón a través de su traducción del Teeteto: se trata del uso que Austin hace de una estrategia como la personificación, según ha podido observarse en estas páginas. Para comprender bien este extremo, es necesario saber que en las traducciones de filosofía ha prevalecido tradicionalmente la domesticación sobre la extranjerización. Ortega y Gasset (2004 [1937], pp. 330-331), al criticar la tendencia sintomática a la domesticación en las traducciones de Platón, pone de relevancia el rasgo que nos interesa:

Cuando se compara con el texto una traducción de Platón, aun la más reciente, sorprende e irrita, no que las voluptuosidades del estilo platónico se hayan volatilizado al ser vertidas, sino que se pierdan las tres cuartas partes de las cosas, de las cosas mismas que actúan en las frases del filósofo y con que este, en su viviente pensar, tropieza, que insinúa o acaricia al paso.

Ortega y Gasset culpaba a las traducciones de Platón del poco interés que el filósofo griego suscita en el lector actual. La traducción de Schleiermacher es una excepción a este respecto porque lo que hizo fue justamente, entre otras cosas, mantener el nivel retórico del texto de Platón, sobre todo en lo que se refiere a la prosopopeya. Es decir, en este sentido Austin sigue tomando como inspiración a los grandes filósofos clásicos griegos en aspectos retóricos tan concretos como este, y con las mismas intenciones discursivas y filosóficas que ellos. Retomando argumentos expresados por Puchner (2010, p. 164), la presencia tan abundante de la personificación en estas filosofías, tan alejadas en el tiempo, tiene mucho que ver con su enfoque teatral. Puchner (2010) cita a Burke para resaltar que "the basic unit of action is the human body in purposive motion" (p. 164). El teatro es una actividad que tiene que ver con la corporalidad y con la agencia humana, así que una metodología filosófica derivada del teatro tendrá que presentar de alguna forma actores humanos, vivos. En el caso de Platón, Puchner tiende a interpretar este mecanismo como la personificación de entidades abstractas en personajes. En el caso de Austin el proceso es parecido: los conceptos de su teoría filosófica van tomando vida en el discurso, aunque sin llegar a conformar personajes definidos, ya que el personaje central de esta obra filosófico-teatral es su propia y personalísima versión del eíron socrático.

\section{Conclusiones}

Tras haber profundizado a través de diferentes estudios en las estrategias con las que Austin conecta el fondo de su teoría filosófica y sus tácticas metodológicas mediante unos potentes modos de expresión retóricos, y después de haber analizado minuciosamente en diversos trabajos el enfoque domesticador de la traducción de How to do things with words al español, se imponía de manera inevitable revisar el influjo en Austin de varios conceptos de la antigüedad griega, canalizados fundamentalmente a través de Platón.

En el presente artículo esta revisión se construye a través de un repaso del concepto de eíron tanto en el teatro griego antiguo como en la filosofía platónica, que lo adopta. Se atiende a la evolución tanto de la palabra como de la idea a lo largo del tiempo y se perfila la peculiar reconstrucción que Austin hace de esta figura al servicio de su filosofía. Al mismo tiempo se dibuja la estrecha relación que existe entre la dualidad eiron/ alazón y la figura del philosophus gloriosus, cuya larga tradición encuentra un reflejo muy significativo en el ámbito anglosajón y en la que podemos decir que Austin y su obra se inscriben de lleno.

El segundo pilar de este panorama de reminiscencias clásicas se centra en concretar el peso del teatro griego en los diálogos platónicos y en determinar cómo esta relación influye en la obra de Austin. Este contraste se realiza comprobando la influencia en Platón de la tragedia por un lado y de la comedia por otro, y observando cómo los recursos del nuevo género mixto platónico (mezcla entre lo serio y lo cómico, gran presencia de la personificación, uso de la aporía, dispersión de la estructura dramática, etc.) dejan una profunda huella en Austin, que no quiere evitar reproducir estos enfoques y estrategias en el desarrollo de su labor filosófica.

En otros estudios (Rodríguez Ponce, 2017a, 2017b, 2018a, 2018b) hemos establecido que emplear estos modelos y recursos retóricos que se salen de lo normativamente establecido para la reflexión y el discurso 
filosóficos les valieron a Austin y a la filosofía del lenguaje ordinario, al conocido como giro lingüistico, la defenestración en el ámbito de la filosofía, aunque luego sus hallazgos pudieran aprovecharse con fortuna en otros terrenos, como la propia lingüística. En el campo de la historia teatral de la filosofía moderna que pretende establecer Puchner (2010, p. 8) sucede algo parecido con Austin. Aunque para nombrar esta nueva disciplina histórico-filosófica se utiliza la etiqueta giro dramático o giro teatral, en clara alusión al giro lingüístico austiniano antes mencionado, Austin no aparece por ninguna parte.

Es cierto que para definir la historia de la filosofía desde un punto de vista teatral y para atestiguar un verdadero influjo dramático platónico en los filósofos Puchner impone unos criterios muy estrictos: habla de que primero tiene que haber un énfasis muy notable en lo teatral, y de que en segundo lugar esta filosofía tiene que articularse a través de personajes inventados nacidos de un impulso dramático y debe considerar sus acciones, decisiones y discursos (Puchner, 2010, p. 122). La obra de Austin no cumple estrictamente todos estos parámetros, pero es innegable que muchas de estas características están reinterpretadas en ella de una manera absolutamente personal y peculiar, y que su influjo dramático platónico es más que evidente a tenor de los aspectos analizados en este trabajo. Puchner (2010, p. 121) afirma que para hablar de giro dramático en filosofía es necesario encontrar filósofos que escriban "con el teatro en la mente". Sería muy injusto arrebatarle a Austin esa virtud, que posee por derecho propio.

\section{ReFERENCiAS}

Amir, L. B. (2013). Philosophy's attitude towards the comic. A re-evaluation. European Journal of Humour Research, $1(1), 6-21$.

Austin, J. L. (1975). How to Do Things with Words: The Williams James Lectures Delivered at Harvard University in 1955. Oxford: Oxford University Press.

Bádenas de la Peña, P. (1984). La estructura del diálogo platónico. Madrid: Instituto Antonio de Nebrija.

Ballart, P. (1994). Eironeía. La figuración irónica en el discurso literario moderno. Barcelona: Quaderns Crema.

Baudelaire, Ch. (1989 [1855]). Lo cómico y la caricatura. Madrid: Visor.

Blumenberg, H. (2000 [1987]). La risa de la muchacha tracia. Madrid: Pre-Textos.

Calero Secall, I. (1988). Luciano: Subasta de vidas. Málaga: Secretariado de Publicaciones de la Universidad de Málaga.

Felman, S. (1983). The Literary Speech Act. Don Juan with J. L. Austin, or Seduction in two Languages. Ithaca: Cornell University Press.

Foran, L. (2012). Introduction. What is the Relation between Translation and Philosophy? En L. Foran (Ed.), Translation and Philosophy (pp. 1-12). Bern: Peter Lang. Doi: https://doi.org/10.3726/978-3-0353-0250-9.

Frye, N. (1957). Anatomy of Criticism. Four essays. New Jersey: Princeton University Press.

García-Hernández, B. (1997). Sinonimia y diferencia de significado. Revista Española de Lingüistica, 27(1), 1-31.

Gooch, P. W. (1997). Socratic Irony and Aristotle's eiron: some puzzles. Phoenix, 41(2), 95-104.

Kahn, C. H. (1996). Plato and the Socratic Dialogue: The Philosophical Use of a Literary Form. Cambridge: Cambridge University Press.

Kuhn, H. (1941). The true tragedy. On the relationship between Greek tragedy and Plato. Harvard Studies in Classical Philology, 52, 1-23.

Lane, M. (2010). Reconsidering Socratic Irony. En D. R. Morrison (Ed.), The Cambridge Companion to Socrates (pp. 237-259). Nueva York: Cambridge University Press. Doi: https://doi.org/10.1017/CCOL9780521833424.

Leiber, J. (1976). How J. L. Austin does things with words. Ph\& Lit, 1(1), 54-65.

Lledó, E. (2015 [1984]). La memoria del logos: estudios sobre el diálogo platónico. Madrid: Taurus.

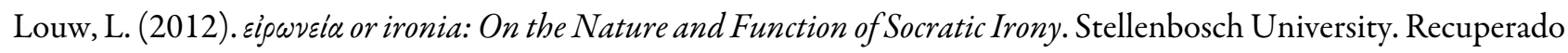
de http://scholar.sun.ac.za.

Martínez Bermejo, M. L. (2013). Las citas de Eurípides en el Gorgias de Platón. Exemplaria Classica, 17, 27-44. 
Miller, J. H. (2001). Speech Acts in Literature. Stanford: Stanford University Press.

Navarro González, J. L. (1992). Luciano: Diálogos de los muertos. Madrid: Gredos.

Nussbaum, M. (2015 [1995]). La fragilidad del bien. Fortuna y ética en la tragedia y la filosofía griega. Madrid: Visor.

Ortega Máñez, M. J. (2012). Socrates as character, Socrates as narrator: Dialogue and representation in Plato. En F. Cooren y A. Létourneau (Eds.), (Re)presentations and dialogue (pp. 289-302). Amsterdam and Philadelphia: John Benjamins. Doi: https://doi.org/10.1075/ds.16.16ort.

Ortega y Gasset, J. (2004 [1937]). Miseria y esplendor de la traducción. En M. Á. Vega (Ed.), Textos clásicos de teoría de la traducción (pp. 323-332). Madrid: Cátedra.

Pabón, J. M. y Fernández Galiano, M. (1969). Platón: La República tomo III. Madrid: Instituto de Estudios Políticos. Pallí Bonet, J. (1985). Aristóteles: Ética Nicomáquea. Madrid: Gredos.

Parker, A. y Sedgwick, E. K. (1995). Performativity and Performance. London: Routledge.

Puchner, M. (2010). The Drama of Ideas. Platonic Provocations in Theater and Philosophy. Oxford: Oxford University Press.

Racket, A. F. (2013). Tragedia, comedia y diálogo socrático: el Banquete entre los géneros teatrales. Emerita, LXXXI(1), 45-64. Doi: https://doi.org/10.3989/emerita.2013.03.1126

Rodríguez Ponce, M. I. (2017a). El discurso académico de John L. Austin: aspectos lingüísticos a la luz de la retórica. RILCE, 33(1), 361-382. Doi: https://doi.org/10.15581/008.33.1.361-82.

Rodríguez Ponce, M. I. (2017b). Aspectos morfosintácticos y léxicos en la traducción al español de How to do things with words. Onomázein, 38, 1-21. Doi: https://doi.org/10.7764/onomazein.38-02.

Rodríguez Ponce, M. I. (2018a). John L. Austin: el papel de la retórica en la periferia de la filosofía. Pensamiento, 74(282), 921-943. Doi: https://doi.org/10.1442/pen.v74.i282.y2018.008.

Rodríguez Ponce, M. I. (2018b). How to do things with words en español: terminología, omisiones y adiciones. Hermeneus, 20, 483-508. Doi: https://doi.org/10.24197/her.20.2018.483-508.

Rorty, R. (1990 [1967]). El giro lingüistico. Dificultades metafilosóficas de la filosofía lingüistica, Barcelona: Paidós.

Salas Abad, C. (2015). El lenguaje visual de Platón y el lenguaje lógico de Wittgenstein: una comparación, Madrid: UNED. Recuperado de http://e-spacio.uned.es/fez/eserv/tesisuned:Filosofia-Csalas/SALAS_ABAD_Carlos_ Tesis.pdf.

Santa Cruz, M. I; Vallejo, Á.; y Cordero, N. L. (1988). Platón: Teeteto. Diálogos V. Madrid: Gredos.

Vlastos, G. (1991). Socrates, Ironist and Moral Philosopher. Ithaca: Cornell University Press.

Warnock, G. J. (1969). John Langshaw Austin: a Biographical Sketch. En K. T. Fann (Ed.), Symposium on J. L. Austin (pp. 3-21). London: Routledge \& Kegan Paul.

Zwagerman, S. (2010). Wit's End. Women's Humor as Rhetorical and Performative Strategy. Pittsburgh: University of Pittsburg Press. DOI: https://doi.org/10.2307/j.ctt9qh4q4.

\section{Notas}

1 Como buen conocedor de la lengua griega, no es extraño que Austin fomentara la alianza entre filosofía y teatro: "The Greek root thea isto be found in the word theorein, which denotes theoretical contemplation, but also in the word theatrom, where it identifies the theater as a place of seeing. In the cave parable, Plato uses precisely this root when he speaks about the drama of sight, thus superimposing seeing and contemplation, theater and theory to form a single activity" (Puchner, 2010, p. 6).

2 De hecho, el impacto que ha tenido después en los estudios literarios, culturales, históricos y artísticos la noción de performatividad (Bal, 2002; Butler, 1997; Felman, 1983; Zwagerman, 2010), especialmente en el teatro, proviene de este matiz teatral en el concepto de performativo (Parker y Sedgwik, 1995, p. 1).

3 Hay cuatro referencias a Sócrates como eíron en los diálogos de Platón: República (336e), Gorgias (489e), Banquete (216e) y Apología (38a), tres en boca de sus oponentes y una en la suya propia. Hay sendas alusiones en las Nubes de Aristófanes y en el Konnos de Ameipsias (Louw, 2012, p. 23). 
4 En este mutatis mutandis, según Gooch, Platón no ahorra en mostrar la fama de Sócrates como eirôn genuino, inclinado a jugar con su interlocutor. Sin embargo, Aristóteles en la Ética a Nicómaco ennoblece el arquetipo del eíron socrático, seguramente por fidelidad a la figura histórica de Sócrates. La eironeía de Sócrates, según Aristóteles, no es la de los bribones y burlones, sino que está más cerca del uso "encantador y cultivado" de las personas amantes de la verdad (Gooch, 1987, p. 99). De hecho, Gooch afirma en este sentido que "Aristotle's Socrates would be more at home in an English novel about Oxbridge philosophers than in Plato's dialogues”, lo que no hace más que reforzar la filiación que hemos establecido entre Sócrates y Austin.

5 Amir $(2013$, p. 8) comenta que la tradición de ridiculización del filósofo académico comienza con Heráclito, que se ríe de sus predecesores, y sigue una línea que abarca a Erasmo, Montaigne, Nietzsche y muchos más.

6 Diógenes se burla de Platón en esa tradición de ridiculización de la filosofía académica (Amir, 2013, p. 8).

7 Según cuenta Diógenes Laercio, Platón era autor teatral (o pretendía serlo) antes de conocer a Sócrates y decidir orientarse hacia la filosofía (Puchner, 2010, p. 4). Por eso tiene la capacidad de reaprovechar todas las estrategias teatrales y retóricas que están a su disposición, a pesar de haber expresado claramente su intención de que la filosofía debía contrarrestar el pernicioso influjo que el teatro tenía sobre el pueblo (Havelock recoge que este tipo de educación sumía a la juventud en un "trance hipnótico" que secuestraba la razón, en Salas Abad, 2015, p. 23); y a pesar de haber expulsado a los poetas de su república ideal y de haber censurado el uso de la retórica porque podía distraer de la verdad filosófica. Hasta esta pretendida contradicción es retomada por Austin en los presupuestos fundamentales de $H T W$, ya que nos dice que hay que desechar del análisis los usos etiolados del lenguaje, pero su obra, en sí misma, es un muestrario de procedimientos constructivos retóricos, teatrales y literarios.

8 Según otras opiniones, de los tres grandes trágicos griegos es Eurípides el que más influye en Platón (Martínez Bermejo, 2013, p. 28).

9 Estos aspectos diferencian bastante a los diálogos del teatro griego estándar. Los diálogos platónicos están basados en los discursos de los personajes individuales y, por ejemplo, el coro queda eliminado. Por otra parte, además de estar escritos en prosa, no estaban pensados exactamente para ser representados en un teatro ante grandes audiencias, sino más bien para ser leídos en voz alta a grupos pequeños (Puchner, 2010, p. 21).

10 En los diálogos de Platón, Sócrates se declara discípulo de Pródico en esta forma de proceder, pero de manera muy socarrona. Al parecer, Platón trata esta faceta de manera bastante irónica, más relacionada con el interés económico de los sofistas. El método de Pródico se conocía como “diéresis de los nombres” (García-Hernández, 1997, pp. 8-10). Busca la diferencia junto a la semejanza aparente de los sinónimos, y muestra gran empeño en emplear la palabra exacta, con un exacerbado afán de distinción de conceptos en pares como adversario/enemigo, injusticia/violencia, suerte/felicidad, pudor/vergüenza... En el recurso a la sinonimia otros sofistas acompañaron a Pródico, como es el caso de Protágoras y Gorgias, que dan nombre a dos de los diálogos más representativos de Platón; y el método de la diéresis ('separación, división') también se empleó para los conceptos en la academia platónica junto con la sinagogé ('reunión, composición'). Es indudable que Austin se sirvió de todas estas inspiraciones en su trabajo, sin desdeñar ninguno de los matices críticos e irónicos que podían aportar.

11 En La risa de la muchach a tracia, a partir de la anécdota de la caída de Tales, H. Blumenberg (2000 [1987]) reflexiona sobre la actitud de incomprensión hacia el investigador teórico a lo largo de la historia del pensamiento occidental. El capítulo IV se titula "El teórico entre lo cómico y lo trágico" y menciona al cínico Bion de Borístenes, que practicaba la filosofía "en bata de payaso", en palabras de Nietzsche. Los cínicos pasan a ocupar el lugar de la muchacha tracia, rebajando al nivel de comedia lo que Tales había mostrado antes con seriedad (Blumenberg, 2000 [1987], pp. 50-52). Austin se mueve en un territorio indefinido entre estos dos extremos, entre el papel de Tales y el de la muchacha tracia.

12 A este respecto es muy significativo este fragmento de Baudelaire en Lo cómico y la caricatura (1989, [1855], p. 28), por el enlace que establece entre la caída y la reflexión filosófica, con su bifocalidad humorística e irónica: "Lo cómico, la potencia de la risa reside en el que ríe, y no en el objeto de la risa. No es el hombre que cae el que ríe de su propia caída, a menos que sea un filósofo, un hombre que haya adquirido, por costumbre, la fuerza de desdoblarse rápidamente y de asistir como espectador desinteresado a los fenómenos de su yo".

13 Además de las obras clásicas griegas, Austin también podría haber tomado otros referentes culturales, incluso del entorno anglosajón, para efectuar una sátira de esta tradición trágica y solemne de la caída y el retorno. Por ejemplo, en su Paraíso perdido John Milton muestra una épica basada en una acción cíclica total: la caída de Satán y Adán (Frye, 1957, p. 320). La catábasis, el descenso al mundo de los muertos, es una figura presente en la épica tradicional (Odisea, Eneida) y también en autores como Dante o el propio Milton (Frye, 1957, p. 321). En el mismo lugar Frye menciona el Endimyon de Keats señalando que baja en busca de la verdad y sube en busca de la belleza, y descubre que son lo mismo. Frye (1957, p. 321) insiste en que la comedia y la ironía manejan un simbolismo paródico (pone como ejemplo la magdalena de Proust y la eucaristía) y subraya que el tema de la parodia enciclopédica es endémico en la sátira, que muestra una relación con la épica y la narrativa: “...we should expect that the containing form of the ironic or satiric epic would be the pure cycle, in which every quest, however successful or heroic, has sooner or later to be made over again” (Frye, 1957, p. 322). 
Exactamente en estos términos enfoca Austin su trabajo filosófico, específicamente con el sentido épico clásico de ciclo, de reinicio constante.

14 "Pisar terreno firme" se corresponde con $\beta \varepsilon \beta \alpha \iota \dot{\sigma} \sigma \eta \tau \alpha \iota$, forma verbal en voz media del verbo $\beta \varepsilon \beta \alpha i o ́ \omega$, probablemente tercera del singular del aoristo de subjuntivo medio. Este verbo significa 'confirmar', 'establecer', pero referido a un argumento, tal y como sucede en el contexto de 7.533 de esta obra, podría traducirse por 'establecer una base firme'. Dado el dominio de Austin en la lengua griega y su manejo de la traducción de textos platónicos, es indudable el influjo directo de esas imágenes metafóricas en el fragmento señalado de $H T W$. El otro sintagma que corrobora esta inspiración platónica de Austin es ßópßopos ("barro", "fango"), en el que incluso hay una marcada similitud fónica entre los términos (bog “pantano”). Agradecemos al profesor Jesús Ureña Bracero su asesoramiento en la traducción y la etimología de estas palabras griegas.

\section{BY-NC-SA}

